\title{
The principles of physical restraint use for hospitalized elderly people: an integrated literature review
}

\author{
Azam Sharifi, Narges Arsalani", Masoud Fallahi-Khoshknab and Farahnaz Mohammadi-Shahbolaghi
}

\begin{abstract}
Background: Physical restraint (PR) is a routine care measure in many hospital wards to ensure patient safety. However, it is associated with many different professional, legal, and ethical challenges. Some guidelines and principles have been developed in some countries for appropriate PR use. The present study aimed to explore the principles of PR use for hospitalized elderly people.

Methods: This was an integrative review. For data collection, a literature search was conducted in Persian and English databases, namely Magiran, Scientific Information Database (SID), Scopus, Google Scholar, Web of Science, and PubMed as well as the websites of healthcare organizations and associations. Eligibility criteria were publication in English or Persian between January 1, 2010, and January 1, 2021, and description of the principles of PR use for hospitalized elderly people. The Preferred Reporting Items for Systematic Reviews and Meta-Analyses (PRISMA) statement was used for document screening and selection, while the critical appraisal tools of the Joanna Briggs Institute (JBI) and the Appraisal of Guidelines for Research and Evaluation II (AGREE II) instrument were used for quality appraisal. The data were analyzed through constant comparison.

Results: Primarily, 772 records were retrieved, while only twenty were eligible for the study. The principles of PR use for hospitalized elderly people were categorized into six main categories, namely principles of education for PR use, principles of decision making for PR use, principles of implementing the PR procedure, principles of monitoring patients with PR, principles of PR use documentation, and principles of PR management.

Conclusion: PR should be used only by trained healthcare providers, with the consent of patient or his/her family members, with standard devices and safe techniques, based on clear guidelines, and under close managerial supervision. Moreover, elderly people with PR should continuously be monitored for any PR-related complications. The findings of the present study can be used for developing clear PR-related guidelines.
\end{abstract}

Keywords: Physical restraint, Integrative review, Principles, Elderly people

\footnotetext{
* Correspondence: na.arsalani@uswr.ac.ir; n.arsalani@yahoo.com Nursing Department, Iranian Research Center on Aging, University of Social Welfare and Rehabilitation Sciences, Tehran, Iran
}

(c) The Author(s). 2021 Open Access This article is licensed under a Creative Commons Attribution 4.0 International License, which permits use, sharing, adaptation, distribution and reproduction in any medium or format, as long as you give appropriate credit to the original author(s) and the source, provide a link to the Creative Commons licence, and indicate if changes were made. The images or other third party material in this article are included in the article's Creative Commons licence, unless indicated otherwise in a credit line to the material. If material is not included in the article's Creative Commons licence and your intended use is not permitted by statutory regulation or exceeds the permitted use, you will need to obtain permission directly from the copyright holder. To view a copy of this licence, visit http://creativecommons.org/licenses/by/4.0/. The Creative Commons Public Domain Dedication waiver (http://creativecommons.org/publicdomain/zero/1.0/) applies to the data made available in this article, unless otherwise stated in a credit line to the data. 


\section{Background}

Medical and health-related advances in the second half of the twentieth century significantly improved life expectancy. Consequently, the global population is progressively aging so that estimates show the global aging population will reach two billions by 2050 [1-4]. Aging is associated with many different health-related problems. Most elderly people suffer from chronic illnesses such as stroke, cancer, diabetes mellitus, dementia, and cardiovascular disease. These problems require frequent hospitalizations [4-7].

Hospitalization is associated with many different adverse events and safety issues because most elderly people suffer from poor health status, cognitive impairments, and functional problems and, hence, are at risk for fall, removal of medical devices connected to the body, and injury to self and others [8-12]. In order to minimize these risks, healthcare providers often use physical restraint (PR) to limit patients' body movements [13-15]. By definition, PR is "any action or procedure that prevents a person's free body movement to a position of choice and/or normal access to his/her body by the use of any method that is attached or adjacent to a person's body and that he/she cannot control or remove easily" [16]. These methods include belts (at the wrist, ankle, chest, waist), bedrails, and chairs [16, 17]. Evidence shows that PR is routinely used in hospitals [1719] and elderly people receive PR during their hospital stay three times more than other hospitalized patients [9]. The prevalence of PR use for hospitalized elderly people is as high as 33-68\% [7].

Although PR is used for safety purposes, studies show that its inappropriate use can endanger patient safety and cause serious physical and mental consequences. Its physical consequences include pressure ulcer, fracture, cardiac dysrhythmia, neuromuscular injuries, urinary and fecal incontinence, asphyxia, and strangulation-induced death [7, 8, 20-22]. The mental consequences of inappropriate PR use include anger, frustration, aggression, fear, humiliation, low self-confidence, delirium, depression, and anxiety $[14,17,23]$. Moreover, it is associated with ethical dilemmas and violates the autonomy and the respect for dignity principles of ethical practice $[24,25]$. It also prolongs the length of hospital stay and increases the risk of fall and nosocomial infections [7, 22, 26]. Besides patients, healthcare providers are also at risk for the consequences of PR use. For instance, a study showed that while the prevalence of violence against healthcare providers was generally $4.5 \%$, it significantly increased to $28 \%$ in case of PR use in pre-hospital settings [27]. PR use also causes negative feelings such as guilt and moral distress for healthcare providers $[9,13,28]$.

Studies show that more than $80 \%$ of healthcare providers have limited knowledge and skills about appropriate
PR use for hospitalized patients [20, 29-33]. Such lack of knowledge and skills not only causes serious problems for patients, but also causes professional, legal, and ethical challenges for healthcare providers. Therefore, clear guidelines are necessary for improving the quality of PR use and reducing its adverse consequences [23, 25, 34]. Several guidelines have so far been developed in this area. Most of these guidelines highlight the importance of maintaining patient's autonomy, involving them in decision making about PR use, and minimizing PR use in healthcare settings [18, 35-38].

PR-related guidelines are context-bound, and hence, those which are appropriate for the needs, priorities, policies, and resources of certain contexts cannot be used in other sociocultural contexts [23, 39-41]. Review studies are needed to make appropriate conclusions and decisions about the principles of appropriate PR use and develop effective PR-related guidelines. Previous studies in this area explored the consequences of PR use $[9,42]$, its legal and ethical requirements [32, 42], the effectiveness of PR-related guidelines [12, 43], and the effectiveness of interventions for minimizing $\operatorname{PR}$ use [7, 22]. However, to the best of our knowledge, none of them comprehensively and systematically described the principles of appropriate PR use. Therefore, the present study was conducted to address this gap. The aim of the study was to explore the principles of PR use for hospitalized elderly people.

\section{Methods}

This integrative review was conducted using the Whittemore and Knafl's method [44, 45]. Initially, we performed a pilot review in order to determine the best literature review strategy for the study. The results of this pilot review revealed that the retrieved data were appropriate for integrative review. Integrative review is an approach which integrates different types of documents and a broad range of methodologies and summarizes available evidence in order to provide a deeper understanding about a given phenomenon. Moreover, it facilitates the integration of theoretical works on the subject of interest $[44,46]$. This approach has five main stages, namely problem identification, literature search, data evaluation, data analysis, and presentation [45].

\section{Stage 1: Problem identification}

The first stage of integrative review is the precise determination of the problem [45]. The present integrative review was conducted to answer the following research question, "What are the principles of PR use for hospitalized elderly people?" 


\section{Stage 2: Literature search}

The first and the second authors of the study independently searched the literature on the principles of PR use for hospitalized elderly people published from January 1 , 2010 , to January 1, 2021. The search was done in the following online databases, Magiran, Scientific Information Database (SID), Scopus, Google Scholar, Web of Science, and PubMed. Moreover, in order to review the grey literature, we searched library resources and the websites of healthcare organizations and associations (Additional file 1) and used the Google search engine to search the World Wide Web. To ensure the comprehensive assessment of the available literature, we also manually searched the reference lists of the retrieved documents. Literature search was performed based on the inclusion criteria shown in Table 1. Search keywords were extracted from the Medical Subject Heading (MeSH) and included "physical restraint," "regulation," "legislation," "rule," "principle," "guideline," "recommendation," "standard," "hospital," "aged," "elderly," and "older adult". Boolean operators "AND" and "OR" were also used. The search protocol was limited to the literature published in either Persian or English. A medical librarian validated the literature search strategy. An example of the literature search strategy is provided in the Additional file 2.

\section{Stage 3: Data evaluation}

Document screening and selection were performed using the Preferred Reporting Items for Systematic Reviews and Meta-Analyses (PRISMA) statement [47]. After excluding duplicate records, the first and the second authors independently assessed the titles and the abstracts of the retrieved documents for eligibility. In case of any uncertainty about the inclusion or the exclusion of any document, its full-text was assessed. Disagreements between the first and the second authors were resolved by the third author. Finally, the first and the second authors independently extracted data about the authors, countries of origin, publication dates, and aims of the studies as well as the principles of PR use for hospitalized elderly people from the included documents and documented in a data collection sheet. Disagreements about data extraction were resolved through discussion.

The first and the second authors independently performed quality appraisal using the critical appraisal tools of the Joanna Briggs Institute (JBI) [48] and the Appraisal of Guidelines for Research and Evaluation II (AGREE II) instrument [49]. Disagreements were resolved by the third author. According to the integrative review method [44, 46, 50], all included studies were included in the final analysis irrespective of their quality appraisal scores.

\section{Stage 4: Data analysis}

In integrative review, collected data are ordered, categorized, and summarized [44]. Based on the study aim and the type of the included documents, the constant comparison method was used for data analysis. As a wellknown method for data analysis, constant comparison helps systematically categorize the data. The method consists of data reduction, data display, data comparison, conclusion drawing, and verification. Constant comparison is an appropriate method for data analysis in integrative reviews due to the wide variety of the data included in the review from documents with diverse methodologies. In this method, extracted data are constantly compared and grouped according to their similarities and finally, findings are described and summarized in the form of categories or themes [44, 46, 51]. For data analysis, the first and the second authors reviewed the full text of each included document for several times, selected appropriate meaning units, and systematically categorized similar meaning units. Finally, their generated categories were assessed, revised, and approved by all members of the research team.

\section{Results}

\section{Stage 5: Presentation}

\section{Characteristics of the documents}

Primarily, 772 documents were retrieved. After assessing the titles and the abstracts of these documents, 679 documents were excluded due to either duplication or irrelevance to the study aim. Finally, the full texts of the remaining 93 documents were assessed for eligibility; 75 documents were excluded due to ineligibility (Additional file 3). Finally, twenty eligible documents were included in the study. Figure 1 shows the PRISMA flowchart of the study.

All included documents were in English language. Additional file 4 presents the characteristics of the

Table 1 Inclusion and non-inclusion criteria

Inclusion criteria

Non-inclusion criteria

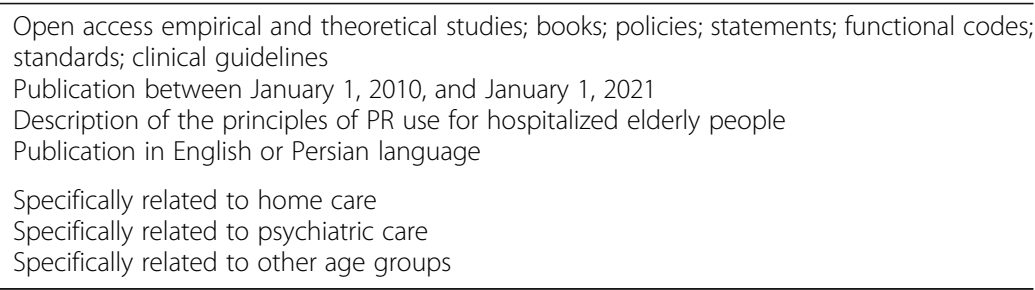




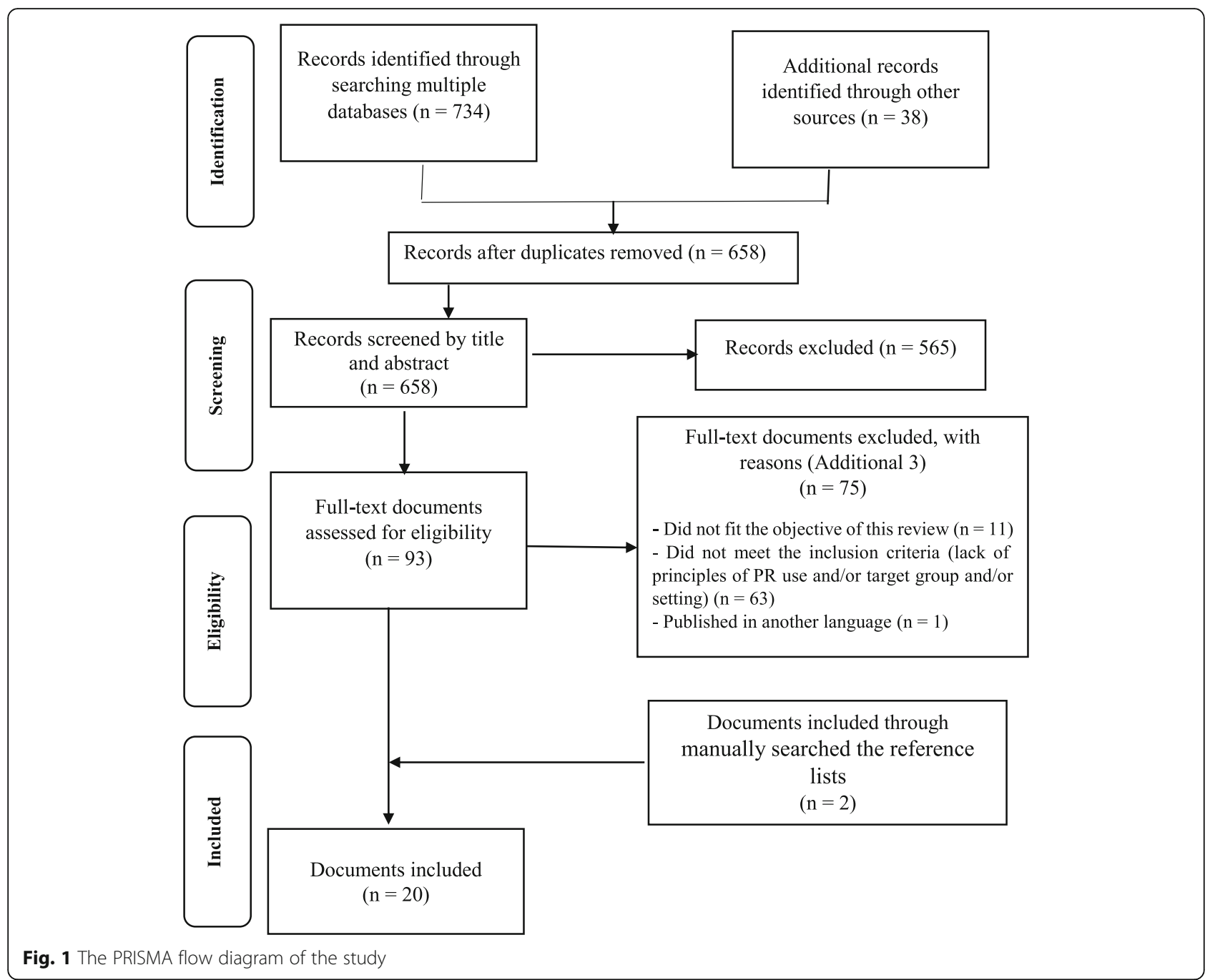

included documents, including data about the authors (individuals and/or organizations), countries of origin, publication dates, types of documents, aims of the studies, and quality scores. Included documents were four guidelines and sixteen journal articles, reports, expert consensus, books, statements, and policy papers which had been developed in the USA $(n=12)$, Canada $(n=3)$, Australia and New Zealand $(n=2)$, Ireland $(n=1)$, Turkey $(n=1)$, and Singapore $(n=$ $1)$. The included documents were of moderate to high quality appraisal based on the critical appraisal tools (JBI and AGREE II) [48, 49].

\section{Principles of PR use for hospitalized elderly people}

In integrative review, findings are described, summarized, and categorized [44, 51]. Accordingly, the principles of PR use for hospitalized elderly people were grouped into six main categories which are explained in the following. Figure 2 shows a visual presentation of the data.

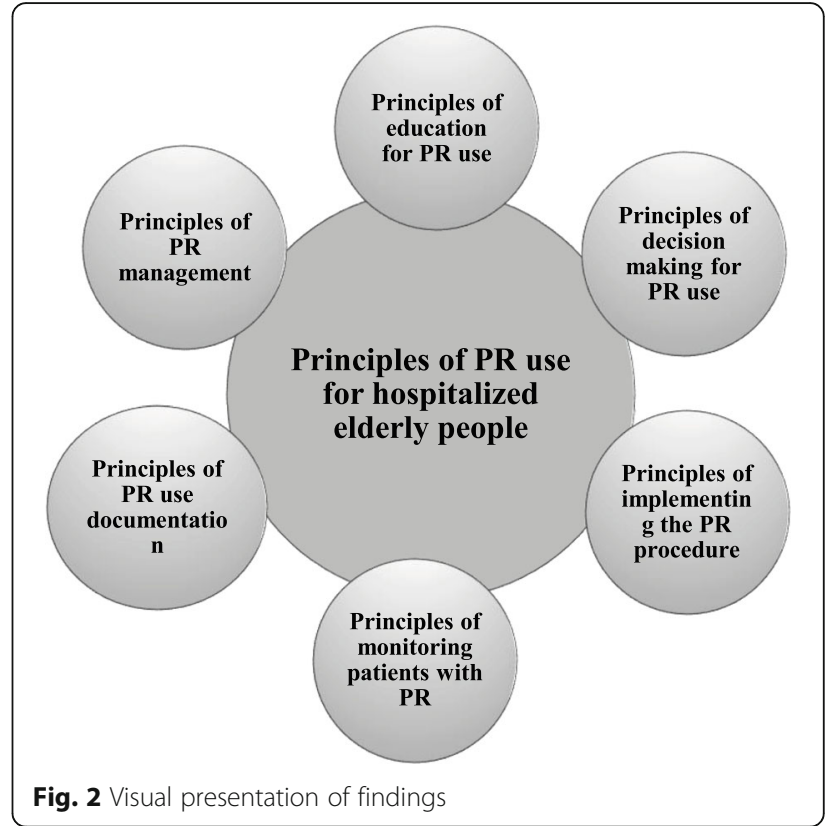




\section{Principles of education for $P R$ use}

One of the most important principles of PR use is to provide PR-related educations to all healthcare providers involved in PR use, including physicians, nurses, auxiliary nurses, and students [30, 35, 37, 43]. Healthcare providers should have adequate knowledge and skills for patient assessment, PR use, and PR outcome evaluation [30]. PR-related educational programs should focus on strategies for the effective management of high-risk situations in order to minimize the need for PR [13, 37]. These strategies include all PR alternatives which may vary according to the resources and equipment of the immediate environment. Moreover, educational programs should cover the principles of intelligent decision making about PR use, its legal and ethical requirements, the responsibilities of individuals involved in PR use, safe and proper PR-related techniques, appropriate physical and mental patient assessment, early diagnosis of PRrelated consequences, and appropriate PR documentation [11, 32, 42]. PR-related educations should be provided during formal university education, at the time of recruitment to the profession, and during in-service continuous education programs through both face-to-face and online courses. In online courses, measures should be taken to clarify probable ambiguities and answer participants' questions. PR-related educations can be provided periodically, for instance $1 \mathrm{~h}$ weekly or $6 \mathrm{~h}$ monthly [32]. The educational managers of hospitals should also keep a record of each healthcare provider's participation in PR-related educational programs in his/ her employment records [11, 32].

\section{Principles of decision making for PR use}

Before PR use, healthcare providers need to assess the intended patient, perform clinical examination, and take his/her complete medical history $[9,10]$. In physical examination and history taking, patient's physical and mental conditions and previous history of fall should carefully be assessed [32, 42]. Moreover, all factors which may cause confusion, wandering, agitation, and aggression should be determined and effectively managed [7, 8]. Unnecessary invasive procedures and connections should also be discontinued and removed as soon as possible because they can cause agitation [11, 36, 52].

There should be rational reasons for PR use [10, 12, 32]. The most important reasons for PR use for hospitalized elderly people are the risks of serious injury to self or others, fall, imbalance, and removal of life support connections (such as endotracheal tube, ventricular catheters, or arterial catheters) [37, 38, 42, 53]. PR should not be used for delirium management because immobility can increase the risk of agitation and injury $[13,54]$. Moreover, PR should never be used in case of staff shortage and environmental unsuitability or for staff convenience and patient punishment $[10,37,38,52]$. The risks associated with PR use should also be weighed against the risks of not using it $[9,13,42]$. In addition, PR should be used as the last resort for ensuring patient safety and when its advantages are greater than its disadvantages and associated risks [7, 35, 37, 43, 55]. Some studies recommended approaches and strategies for minimizing PR use which are shown in Table 2. Of course, some of these strategies may incur some costs. Healthcare providers should select and use the best strategies based on the immediate environment and sociocultural and economic conditions [7, 8, 18, 22].

Another principle of decision making for PR use is to consider the opinions and preferences of patients, their surrogates, and their families. They have the right to know the reasons for PR use and its benefits and potential risks. Therefore, they should adequately be informed and their informed consent should be obtained [10-12, 32, 36, 37, 42]. Most studies highlighted that PR should be used only with medical order $[10,11,36,42]$. In emergency situation which physicians may not be accessible, nurses can use PR without medical order and families' consent but they should obtain medical order and inform family members about patients' conditions as soon as possible $[9,11]$. Some studies noted that besides physicians, registered nurses or medical assistants can also prescribe PR [32, 38]. Nonetheless, PR-related decisions should be made collaboratively and the

Table 2 Approaches and strategies for minimizing PR use

\begin{tabular}{ll}
\hline Approaches & Strategies \\
\hline Psychological support & $\begin{array}{l}\text { Establishing relationship with patient and his/her family members to collect data about his/her } \\
\text { daily habits and behaviors; increasing family members' attendance at patient bedside; emotional } \\
\text { support; stress management; coping enhancement }\end{array}$ \\
& $\begin{array}{l}\text { Removing unnecessary connections; fulfilling patient's needs; pain management; medication } \\
\text { management }\end{array}$ \\
Physiological support & $\begin{array}{l}\text { Using motion sensors, alarms, low-low beds, and floor pads; reducing environmental stimuli; } \\
\text { continuous patient monitoring }\end{array}$ \\
Managerial and organizational measures & $\begin{array}{l}\text { Modifying organizational culture to reduce PR use; increasing nurse-patient ratio; promoting } \\
\text { managerial supervision; providing healthcare providers with clinical guidelines; providing nurses } \\
\text { and physicians with educations about PR use, its legal and ethical considerations, and its adverse } \\
\text { consequences; and modifying PR-related attitudes }\end{array}$ \\
\hline
\end{tabular}


opinions of all members of healthcare team should be considered $[10,11,36,42]$.

\section{Principles of implementing the PR procedure}

The devices and equipment for implementing the PR procedure should be standard, comfort, safe, and appropriate in size and should be made with soft and flexible materials, particularly foamed plastic or sheep skin. The PR procedure should never be implemented using clothes, bed sheets, or bandage. Moreover, PR-related devices and equipment should be equipped with locks which are easily opened or knots which are easily untied, should be made in various sizes, and should be used based on their user manuals [18, 36-38]. The PR procedure should also be implemented using safe and appropriate procedures $[12,18,36-38,56,57]$. The following points should be taken into account when implementing the PR procedure:

- Patient's bed or chair should be locked and set at the lowest possible height.

- Patient should be positioned in proper body alignment in order to prevent neurovascular injuries.

- Primarily, devices should be used that apply the lowest level of immobility. Examples of these devices are gloves and elbow immobilizers.

- PR devices should be appropriate for patient size.

- The body surface on which PR is applied should be regularly assessed.

- PR should not be applied on catheters connected to the patient.

- At most two limbs should be restrained at any given time and the four limbs should never be restrained simultaneously.

- Bony prominences should be protected using pads in order to prevent tissue injury.

- PR devices should be connected to bed so that they freely move along with changes in the elevation of the head of bed.

- PR devices should never be fastened tightly because they may reduce blood flow to the limbs.

- PR devices should be fixed with knots which are easily untied so that they can easily be removed in emergency situations.

\section{Principles of monitoring patients with $P R$}

The monitoring of elderly people with PR should be performed using an individualized care plan and by registered nurses $[10,11,35]$. In this plan, patient's physical and mental conditions should regularly be assessed every 15-30 min. In physical patient monitoring, the functions of the respiratory system (respiratory rate and rhythm), cardiovascular system (heart rate and rhythm, blood pressure, and capillary refilling), integumentary system (color, temperature, wound, edema), nervous system (sense and mobility of distal tissues and level of consciousness), and connected catheters (if any) should be carefully assessed. In mental patient monitoring, patient should be assessed for the symptoms of fear, humiliation, anger, and aggression [12, 32, 36-38]. Moreover, basic needs related to nutrition, hydration, hygiene, and elimination should be assessed and fulfilled [36, 37, 42, 52] based on the ethical principles of PR use including respect for self-esteem and privacy [7, 11, 32].

Some studies recommended the monitoring of elderly people under PR using closed-circuit television cameras or direct observation [35-37, 42]. Patient should be continuously monitored by registered nurses respecting any need for PR discontinuation $[7,11,32]$. PR should be used for a short period of time and discontinued as soon as patient's need for PR is eliminated [7, 38, 42, 56]. Some studies reported that PR for elderly people should not be used for more than $4 \mathrm{~h}[37,42]$. During each 2-h course of PR use, PR should be removed for 10-15 min and patient's response to it should be frequently assessed $[7,11,32]$. PR should immediately be removed in case of any PR-related complication [32, 37]. Healthcare providers should also monitor patients throughout the $24 \mathrm{~h}$ after PR removal respecting any PR-related complications or death [37].

\section{Principles of $P R$ use documentation}

All PR-related care measures should clearly be documented in patient's medical records [9-12, 35-37, 42]. PR-related documentation should include:

- Any unsuccessful measure for using PR alternatives to manage high-risk behaviors of the intended patient

- Reasons for PR use

- Medical order for PR with details about the time at which PR is applied and removed, the number of the restrained limbs, and the type of devices used for PR (Note: any PRN order for PR use should be avoided)

- The consent of patient, family members, or surrogate for PR use

- Patient's physical and mental conditions before, during, and after PR use

- The process of physical and mental assessment before, during, and after PR use

- Patient's response to PR

- Any injury or death from the beginning of PR use up to 24 hours after its removal

\section{Principles of PR management}

The management system of hospitals should develop plans and strategies for eliminating PR use. One of the principles of PR management is to support PR-free care 
using safety procedures $[8,11,18,30,43]$. In collaboration with healthcare providers, hospital managers should develop clear policies and guidelines for PRrelated decision making and procedures. Such policies should be available in written format for all healthcare providers in healthcare settings [10, 37, 38]. Moreover, hospital managers should periodically assess all documents related to PR use for elderly people [37].

\section{Discussion}

This study aimed to explore the principles of PR use for hospitalized elderly people. Twenty qualified documents were analyzed in the study. Findings revealed that these principles are related to education and decision making for PR use, implementing the PR procedure, monitoring patients with $\mathrm{PR}$, documenting $\mathrm{PR}$ use, and managing PR use.

Adequate care-related knowledge is among the most basic requirements of any quality healthcare-related measure. Nonetheless, studies show that physicians and nurses have limited knowledge about PR use [18, 20, 31-33, 58]. A study showed that $85 \%$ of nurses and $90 \%$ of physicians had received no PR-related education [33]. Therefore, adequate quality education about the principles of appropriate PR use for elderly people should be provided to all healthcare providers. Such educations can reduce the use and the complications of PR $[7,58,59]$. Of course, pure education programs cannot guarantee safe PR-related practice $[9,23,53]$ and adequate staffing, quality devices and equipment, and PR alternatives are needed to reduce the use and the complications of PR.

The second main category of the study was related to the principles of decision making for PR use. The most important point in making PR-related decisions is that PR should be considered as the last resort for ensuring patient safety. Nonetheless, evidence shows that PR is used as an accessible and routine option to reduce workload in case of staff shortage [11, 17, 20, 58-60], create a sense of security among healthcare providers, and even impose discipline or punishment on patients [7, 17, 60]. Such uses of PR contradict the principles of ethical practice. Studies show that PR-related decision making is affected by a wide range of factors such as care delivery environment, healthcare providers' knowledge and attitude, managerial regulations, and cultural context [28, 53, 61-64]. All these factors should be taken into account while developing PR-related guidelines and protocols. Moreover, PR-related decisions should be made by a multidisciplinary team. In other words, the responsibility of PR use needs to be carried by all healthcare providers $[10,12]$. However, some studies reported PR use as an independent nursing intervention, denoting that other healthcare providers do not participate in PRrelated decision making $[17,32,60,61]$. Therefore, PR- related complications can cause professional, legal, and ethical consequences for nurses. In order to prevent these consequences, all healthcare providers should be involved in decision making about PR use. We also found that PR should be used with the consent of the intended patient, his/her family members, or his/her surrogate. Contrary to this finding, some studies showed that PR is used without any consent $[24,31,60,65,66]$. Therefore, PR-related guidelines and protocols should include items on patient consent and hospital managers are recommended to exercise closer supervision in this area.

The third main category of the principles of PR use for elderly people was related to the principles of implementing the PR procedure. This procedure should be implemented using standard PR-specific devices. All healthcare providers should also receive adequate education about their appropriate use [30, 32, 35]. Nonetheless, a study reported the use of non-standard and inappropriate devices for PR and showed that PRs had been attached to side rails instead of bed frame in $91 \%$ of cases [60]. Such practice violates the principles of safe PR use because attaching PR devices to side rails may cause serious injuries to the restrained limb in case of the sudden fall of side rails. Another study also showed that $86.7 \%$ of nurses had poor PR-related practice [58]. Evidence showed that using nonstandard devices and unsafe techniques for PR can cause patients injuries and even death [21,32,60]. Therefore, hospital managers and authorities are recommended to provide healthcare providers with standard devices and clear guidelines for PR use.

Principles of monitoring patients with PR were the fourth main category of the study. Physical and mental monitoring of elderly people with PR should be performed using a regular, comprehensive, and individualized care plan. A study found that for most patients, PR is not immediately removed after agitation is managed and is continued without any rational reason [67]. Another study reported that in $46.9 \%$ of cases, nurses did not regularly perform skin assessment [68] and the most common complications related to inappropriate patient monitoring were agitation (72\%) and impaired skin integrity (55.9\%) [20]. Evidence shows that poor monitoring of patients with PR can negatively affect patient safety, increase the likelihood of medical errors, and cause different complications $[7,10,13,58,60]$. Therefore, all healthcare providers, particularly nurses, are recommended to pay more careful attention to patient monitoring during PR use.

The fifth main category of the study was related to the principles of PR documentation. Documentation of therapeutic and caring measures in patients' medical records is a professional and legal responsibility of all healthcare providers, and patients' medical records are a 
valuable source for safe and quality care delivery [69]. However, evidence shows that more than $70 \%$ of healthcare providers do not document PR use [58, 60, 66, 70]. A study showed that most physicians did not document PR-related orders in patients' medical records. Consequently, nurses also avoid PR documentation due to their fear over the legal consequences of PR use [60]. Lack of PR documentation in patients' medical records results in the lack of any evidence for assessing the quality and the complications of PR use. Therefore, quality education and managerial supervision are needed to promote PR documentation.

The six main category of the study was the principles of PR management. Hospital management system should develop plans to reduce PR use and support PR-free care. Evidence shows that clear PR-related guidelines and protocols can reduce healthcare providers' uncertainties over PR use and improve care quality $[18,58$, 66]. Moreover, regular managerial supervision of healthcare providers' PR-related practice is among the major factors contributing to quality care. Lack of such supervision can result in increased use of PR [23, 60, 63]. Establishment of committees on PR use in hospitals is recommended in order to promote PR-free care and supervise healthcare providers' PR-related practice.

\section{Limitations}

One of the limitations of this study was our limited access to some databases. Moreover, this study only reviewed studies published in English and Persian. Although all documents included in the study had acceptable quality, the results of the present study should be used and generalized to other settings cautiously.

\section{Conclusion}

PR is a high-risk and complex care measure and, hence, should be used based on clear principles and guidelines. This study suggests that all healthcare providers should receive quality PR-related education, make PR-related decisions in collaboration with patients and their family members, use standard and safe devices and techniques for PR, continuously monitor patients with PR, and carefully document all PR-related care measures in patients' medical records. Moreover, managers and authorities in all hospitals should provide healthcare providers with clear guidelines for using PR. The findings of the present study can be used for developing culturally-appropriate PR-related guidelines and can be used in nursing research, practice, education, and management.

\section{Abbreviations}

PR: Physical restraint; SID: Scientific Information Database; MeSH: Medical Subject Heading; PRISMA: Preferred Reporting Items for Systematic Reviews and Meta-Analyses; JBI: Joanna Briggs Institute; AGREE: Appraisal of Guidelines for Research and Evaluation

\section{Supplementary Information}

The online version contains supplementary material available at https://doi. org/10.1186/s13643-021-01676-8.

Additional file 1. Websites of health care organizations and associations. Websites of health care organizations and associations included in the search.

Additional file 2. An example of the literature search strategy. An Example of search strategy used in the literature database of PubMed.

Additional file 3. List of excluded documents. List of excluded documents after full-text eligibility assessment.

Additional file 4. Characteristics of the included documents. The characteristics of documents included in the present study.

\section{Acknowledgements}

This review is part of the Ph.D. thesis in nursing. We would like to thank the Vice-chancellor of the University of Social Welfare and Rehabilitation Sciences, Tehran, Iran, for approval and financial support of this study. We are grateful to Professor Abbas Ebadi at the Behavioral Sciences Research Center, Life Style Institute, Baqiyatallah University of Medical Sciences, Tehran, Iran, who reviewed the manuscript before submission.

\section{Authors' contributions}

All authors had significant roles in designing, conceiving, and conducting the study and drafting the manuscript. AS, NA, MFK, and FMS contributed in designing the study. AS, NA, and MFK were responsible for searching, screening, and selecting studies. FMS was critical reader and reviser of the manuscript. All authors read and approved the final manuscript.

Funding

The authors disclosed receipt of the following financial support for the research, authorship, and/or publication of this article: This research was funded by a grant from the University of Social Welfare and Rehabilitation Sciences, Tehran, Iran (grant number: 982518).

Availability of data and materials

The datasets used and/or analyzed during the current study are available from the corresponding author on reasonable request.

\section{Declarations}

Ethics approval and consent to participate IR.USWR.REC.1398.121.

Consent for publication

Not applicable.

\section{Competing interests}

The authors declare that they have no competing interests.

Received: 16 September 2020 Accepted: 15 April 2021

Published online: 01 May 2021

\section{References}

1. Arsalani N, Nobahar M, Ghorbani R, Kia NS, Etemadi M. Nutrition status and its relationship with depression in elderly pepople. Koomesh. 2017;19(2): 401-11.

2. Arsalani N, Nobahar M, Ghorbani R, Kia NS, Etemadi M. Cognitive disorders and some associated social factors in elderly pepole. Koomesh. 2018;20(2): 240-7.

3. Kazemi N, Sajjadi H, Bahrami G. Quality of life in Iranian elderly. Salmand. 2019;13(Special Issue):518-33.

4. Aseyedali M, Sadeghi-Mahalli N, Norouzi-Tabrizi K. A review on adult daycare centers in the world. Salmand. 2019;13(4):518-29.

5. Sharifi A, Arsalani N, Fallahi-Khoshknab M, Mohammadi-Shahbolaghi F, Ebadi A. Iranian nurses' perceptions about using physical restraint for hospitalized elderly people: a cross-sectional descriptive-correlational study. BMC Geriatr. 2020;20(1):233. https://doi.org/10.1186/s12877-020-01636-2.

6. Javadian SR. Old age social work. Quart J Soc Work. 2016;4(2):27-32. 
7. Lim SC, Poon WH. Restraint use in the management of the ederly with Dementia in hospital. Internal Med Res Open J. 2016;1(2):1-4.

8. Cotter VT, Evans LK. Try this: avoiding restraints in hospitalized older adults with dementia. Hartford Inst Geriatr Nurs. 2018. Available from: https:// consultgeri.org/try-this/dementia/issue-d1.pdf.

9. Said AA, Kautz DD. Reducing restraint use for older adults in acute care. Nursing. 2013;43(12):59-61. https://doi.org/10.1097/01.NURSE.0000437484. 75992.ca.

10. Dikiciyan J. Australian and New Zealand Society for Geriatric Medicine Position Statement Abstract: Physical restraint use in older people. Australas J Ageing. 2016;35(3):225.

11. American Nurses Association (ANA). Reduction of patient restraint and seclusion in health care settings. 2012. Available from: https://www. nursingworld.org/ 4af287/globalassets/docs/ana/ethics/ps_reduction-of-pa tient-restraint-and-seclusion-in-health-care-settings.pdf

12. Zencirci AD. Use of physical restraints in neurosurgery: guide for a good practice. In explicative cases of controversial issues in Neurosurgery. 2012. Available from: http://www.intechopen.com/books/explicative-cases-ofcontroversial-issues-in\%20neurosurgery/use-of-physical-restraints-inneurosurgery-guide-for-a-good-practice.

13. Hazzard WR. Hazzard's geriatric medicine and gerontology. $7^{\text {th }}$ edition. Edited by Halter JB, Ousander JG, Studenski S, High KP, Asthana S, et al. New York: McGraw-Hill Education Medical; 2017.

14. Fariña-López E, Estévez-Guerra GJ, Polo-Luque ML, Pogrányivá AH, Penelo E. Physical restraint use with elderly patients: perceptions of nurses and nursing assistants in Spanish acute care hospitals. Nurs Res. 2018;67(1):55-9. https://doi.org/10.1097/NNR.0000000000000252.

15. Long SJ, Brown KF, Ames D, Vincent C. What is known about adverse events in older medical hospital inpatients? A systematic review of the literature. Qual Assur Health Care. 2013;25(5):542-54. https://doi.org/10.1093/ intghc/mzt056.

16. Bleijlevens MH, Wagner LM, Capezuti E, Hamers JP, Workgroup IPR. Physical restraints: Consensus of a research definition using a modified delphi technique. J Am Geriatr Soc. 2016;64(11):2307-10. https://doi.org/10.1111/ jgs.14435.

17. Jiang H, Li C, Gu Y, He Y. Nurses' perceptions and practice of physical restraint in China. Nurs Ethics. 2015;22(6):652-60. https://doi.org/10.1177/ 0969733014557118.

18. Lach HW, Leach K, Butcher HK. Evidence-based practice guideline. Changing the practice of physical restraint use in acute care. J Gerontol Nurs. 2016; 42(2):17-26. https://doi.org/10.3928/00989134-20160113-04.

19. Eltaliawi AG, El-Shinawi M, Comer A, Hamazah S, Hirshon JM. Restraint use among selected hospitalized elderly patients in Cairo, Egypt. BMC Res Notes. 2017;10(1):633. https://doi.org/10.1186/s13104-017-2978-x.

20. Guvercin CH, Samur M, Gurkan KP. The other side of the coin: nurses' views and behavior on physical restraint. Acta Bioethica. 2018;24(2):253-64. https://doi.org/10.4067/S1726-569X2018000200253.

21. Berzlanovich AM, Schopfer J, Keil W. Deaths due to physical restraint. Dtsch Arztebl Int. 2012;109(3):27-32. https://doi.org/10.3238/arztebl.2012. 0027.

22. Möhler R, Nürnberger C, Abraham J, Köpke S, Meyer G. Interventions for preventing and reducing the use of physical restraints of older people in general hospital settings. Cochrane Database Syst Rev. 2016;2016(12): CD012476. https://doi.org/10.1002/14651858.CD012476.

23. Leahy-warren P, Varghese V, Day MR, Curtin M. Physical restraint: perceptions of nurse managers, registered nurses and health care assistants. Int Nurs Rev. 2018;65(3):327-35. https://doi.org/10.1111/inr.12434.

24. Crutchfield P, Gibb TS, Redinger MJ, Ferman D, Livingstone J. The conditions for ethical application of restraints. Chest. 2019;155(3):617-25. https://doi.org/10.1016/j.chest.2018.12.005

25. Muir-Cochrane E, Baird J, McCann T. Nurses' experiences of restraint and seclusion use in short-stay acute old age psychiatry inpatient units: a qualitative study. J Psychiatr Ment Health Nurs. 2015;22(2):109-15. https:// doi.org/10.1111/jpm.12189.

26. Bai X, Kwok TCY, Ip IN, Woo J, Chui MYP, Ho FKY. Physical restraint use and older patients' length of hospital stay. Health Psychol Behav Med. 2014;2(1): 160-70. https://doi.org/10.1080/21642850.2014.881258.

27. Cheney PR, Gossett L, Fullerton-Gleason L, Weiss SJ, Ernst AA, Sklar D. Relationship of restraint use, patient injury, and assaults on EMS personnel. Prehosp Emerg Care. 2006;10(2):207-12. https://doi.org/10.1080/1090312 0500541050
28. Hevener S, Rickabaugh B, Marsh T. Using a decision wheel to reduce use of restraints in a medical-surgical intensive care unit. Am J Crit Care. 2016;25(6): 479-86. https://doi.org/10.4037/ajcc2016929.

29. Penelo E, Estévez-Guerra GJ, Fariña-López E. Validity and measurement invariance of the Physical Restraint Use Questionnaire (PRUQ) in nursing staff. J Clin Nurs. 2018;27(5-6):e1179-88. https://doi.org/10.1111/jocn.14253.

30. American Academy of Nursing. Choosing wisely: physical restraints. 2014. Available from: https://www.aannet.org/initiatives/choosing-wisely/physicalrestraints.

31. Moradimajd P, Noghabi AA, Zolfaghari M, Mehran A. Physical restraint use in intensive care units. Iran J Crit Care Nurs. 2015;8(3):173-8.

32. Cleary KK, Prescott $K$. The use of physical restraints in acute and long-term care: an updated review of the evidence, regulations, ethics, and legality. J Acute Care Phys Ther. 2015;6(1):8-15. https://doi.org/10.1097/JAT. 0000000000000005

33. Kalula SZ, Petros SG. Use of physical restraint in hospital patients: a descriptve study in a tertary hospital in South Africa. Curatonis. 2016;39(1): a1605.

34. Saeidi S, Khatiban M, Khazaei A, Soltanian A, Rahimi-Bashar F. Assessment of intensive care unit nurses' knowledge, attitude, and practice of physical restraint use. Sci J Hamadan Nurs Midwifery Fac. 2015;23(3):40-9.

35. McNeill S, White V, An D, Legere L, Rey M, Toor GK, et al. Delirium, dementia, and depression in older adults: assessment and care. Toronto: Registered Nurses' Association of Ontario (RNAO); 2016. Available from: https://rnao.ca/sites/rnaoca/files/bpg/RNAO_Delirium_Dementia_ Depression_Older_Adults_Assessment_and_Care.pdf

36. Wagner LM, Perivolaris A, Boaro N, Casselman L, Carreau L, Edgar S, et al. Promoting safety: alternative approaches to the use of restraints. Toronto: Registered Nurses' Association of Ontario (RNAO); 2012. Available from: https://rnao.ca/sites/rnaoca/files/Promoting_Safety_Alternative_Approaches_ to_the_Use_of_Restraints_o.pdf

37. Health Service Executive (HSE). Policy on the use of physical restraints in designated residential care units for older people. 2011. Available from: https://www.hse.ie/eng/about/who/qid/socialcareapplframework/policy-onthe-use-of-physical-restraints-in-desinated-residential-care-units-for-op.pdf.

38. Snook AG, Richman S. Physical Restraint Use. Cinahl Inform Syst. 2017; Available from: https:/www.ebscohost.com/assets-sample-content/Physical_ Restraint_Use.pdf.

39. Snook AG, Richman S. Physical Restraint Use. California: Cinahl Information Systems; 2017. Available from: https://www.ebscohost.com/assets-samplecontent/Physical_Restraint_Use.pdf.

40. Jacobson P. Transforming clinical practice guidelines into legislative mandates: proceed with abundant caution. JAMA. 2008;299(2):208-10. https://doi.org/10.1001/jama.2007.12.

41. Goud R, Hasman A, Strijbis A, Peek N. A parallel guideline development and formalization strategy to improve the quality of clinical practice guidelines. Int J Med Inform. 2009;78(8):513-20. https://doi.org/10.1016/j.jjmedinf.2009. 02.010 .

42. Agens JE. Chemical and Physical restraint use in the older person. Br J Med Pract. 2010;3(1):302.

43. Lachance C, Wright MD. Avoidance of physical restraint use among hospitalized older adults: a review of clinical effectiveness and guidelines. Ottawa: Canadian Agency for Drugs and Technologies in Health (CADTH); 2019.

44. Whittemore R, Knafl K. The integrative review: updated methodology. J Adv Nurs. 2005;52(5):546-53. https://doi.org/10.1111/j.1365-2648.2005.03621.x.

45. Whittemore R. Combining evidence in nursing research: methods and implications. Nurs Res. 2005;54(1):56-62. https://doi.org/10.1097/00006199-2 00501000-00008.

46. Hopia H, Latvala E, Liimatainen L. Reviewing the methodology of an integrative review. Scand J Caring Sci. 2016;30(4):662-9. https://doi.org/1 $0.1111 /$ scs. 12327

47. Moher D, Liberati A, Tetzlaff J, Altman DG. Preferred reporting items for systematic reviews and meta-analyses: The PRISMA statement. PLoS Med. 2009;6(7):264-9.

48. McArthur A, Klugárová J, Yan H, Florescu S. Innovations in the systematic review of text and opinion. Int J Evid Based Healthc. 2015;13(3):188-95. https://joannabriggs.org/sites/default/files/202008/Checklist_for_Text_and_ Opinion.pdf. https://doi.org/10.1097/XEB.0000000000000060.

49. AGREE Next Steps Consortium. AGREE II. Instrument voor de beoordeling van richtlijnen. 2009. 
50. Brouwers M, Kho ME, Browman GP, Cluzeau F, feder G, Fervers B, Hanna S, Makarski J on behalf of the AGREE Next Steps Consortium. AGREE II: Advancing guideline development, reporting and evaluation in healthcare. Can Med Assoc J. 2010;182:E839-842:1-3. https://doi.org/10.1503/cmaj.090449.

51. Soares CB, Hoga LAK, Peduzzi M, Sangaleti C, Yonekura T, Silva DRAD. Integrative review: concepts and methods used in nursing. Rev Esc Enferm USP. 2014;48(2):329-39.

52. Peisah C, Chan DK, McKay R, Kurrle SE, Reutens SG. Practical guidelines for the acute emergency sedation of the severely agitated older patient. Intern Med J. 2011;41(9):651-7. https://doi.org/10.1111/j.1445-5994.2011.02560.x.

53. Mohler R, Meyer G. Attitudes of nurses towards the use of physical restraints in geriatric care: a systematic review of qualitative and quantitative studies. Int J Nurs Stud. 2014;51(2):274-88. https://doi.org/10.1016/j.jijnurstu.2013.10.004.

54. Flaherty JH, Little MO. Matching the environment to patients with delirium: lessons learned from the delirium room, a restraint free environment for older hospitalized adults with delirium. J Am Geriatr Soc. 2011;59(s2):S295300. https://doi.org/10.1111/j.1532-5415.2011.03678.x.

55. American Geriatrics Society (AGS). Ten things clinicians and patients should question. 2015. Available from: https://www.choosingwisely.org/wpcontent/uploads/2015/02/AGS-Choosing-Wisely-List.pdf.

56. American Family Physician. Choosing wisely: don't use physical restraints to manage behavioral symptoms of hospitalized older adults with delirium. 2020. http://www.aafp.org/afp/recommendations/viewRecommendation. htm?recommendationld $=190$

57. Potter PA, Perry AG, Stockert P, Hall A. Fundamentals of Nursing - E-Book. 10th edition. Amsterdam: Elsevier Health Sciences; 2020.

58. Younis GA, Ahmed SE. Physical restraint and maintenance of critically ill patient's safety in intensive care unit: effect of clinical practice guidelines on nurse's practice and attitude. IOSR-JNHS. 2017;6(4):6-21.

59. Lan SH, Lu LC, Lan SJ, Chen JC, Wu WJ, Chang SP, et al. Educational intervention on physical restraint use in long-term care facilities - systematic review and meta-analysis. Kaohsiung J Med Sci. 2017;33(8):411-21. https:// doi.org/10.1016/j.kjms.2017.05.012.

60. Saeidi S, Khatiban M, Khazaei A, Soltanian A, Rahimi-Bashar F. Assessment of the patients' physical restraint standards status and its related factors in the critical care units of the Educational \& Medical Hospitals of Hamadan University of Medical Sciences [MSc thesis]. Hamadan: Hamadan University medical science; 2015.

61. Casterle BD, Goethals S, Goethals C. Contextual influences on nurses' decision-making in cases of physical restraint. Nurs Ethics. 2014:1-10.

62. Raveesh B, Lepping P. Restraint guidelines for mental health services in India. Indian J Psychiatry. 2019;61(s):698-705.

63. Springer $\mathrm{G}$. When and how to use restraint. Learn about possible indications for restraint, types of restraints, and how to monitor patients in restraint. Am Nurse Today. 2015;10(1):26-7.

64. Hofmann H, Schorro E, Haastert B, Meyer G. Use of physical restraints in nursing homes: a multicentre cross-sectional study. BMC Geriatr. 2015;15(1): 129. https://doi.org/10.1186/s12877-015-0125-x.

65. Azab SM, Negm LA. Use of physical restraint in intensive care units (ICUs) at Ain Shams University Hospitals, Cairo. J Am Sci. 2013;9(4):230-40.

66. Gu T, Wang X, Deng N, Weng W. Investigating influencing factors of physical restraint use in China intensive care units: a prospective, crosssectional, observational study. Aust Crit Care. 2019;32(3):193-8. https://doi. org/10.1016/.jaucc.2018.05.002.

67. Rose L, Dale C, Smith OM, Burry L, Enright G, Fergusson D, et al. A mixedmethods systematic review protocol to examine the use of physical restraint with critically ill adults and strategies for minimizing their use. Syst Rev. 2016;5(1):194. https://doi.org/10.1186/s13643-016-0372-8.

68. Mahmoud AS. Psychiatric nurses' attitude and practice toward physical restraint. Arch Psychiatr Nurs. 2016;31(1):2-7. https://doi.org/10.1016/j.apnu.2 016.07.013.

69. Azevedo OA, Guedes ES, Araújo SAN, Maia MM, Cruz DALM. Documentation of the nursing process in public health institutions. Rev Esc Enferm USP. 2019:53:e03471. https://doi.org/10.1590/s1980-220x2018003703471.

70. Kandeel NA, Attia AK. Physical restraints practice in adult intensive care units in Egypt. Nurs Health Sci. 2013;15(1):79-85. https://doi.org/10.1111/nhs.12000.

\section{Publisher's Note}

Springer Nature remains neutral with regard to jurisdictional claims in published maps and institutional affiliations.

\section{Ready to submit your research? Choose BMC and benefit from}

- fast, convenient online submission

- thorough peer review by experienced researchers in your field

- rapid publication on acceptance

- support for research data, including large and complex data types

- gold Open Access which fosters wider collaboration and increased citations

- maximum visibility for your research: over $100 \mathrm{M}$ website views per year

At BMC, research is always in progress.

Learn more biomedcentral.com/submissions 